\title{
Genotoxicity and oxidative stress induced by the orally administered nanosized nickel and cobalt oxides in male albino rats
}

\author{
Atef Abdel-Moneem $\mathrm{Ali}^{i^{*}}$ and Hanan Ramadan Hamed Mohamed ${ }^{2}$
}

\begin{abstract}
Background: Nanoparticles (NPs) are extensively used in many areas of our daily life. Thus, human exposure to a mixture of the NPs is likely to occur. However, most of the previous studies have investigated the toxicity of the individual NPs. Therefore, the current study investigated the genotoxicity and oxidative stress induced by an acute oral administration of the nano-sized nickel oxide $(\mathrm{NiO})$ and/or cobalt oxide $\left(\mathrm{CO}_{3} \mathrm{O}_{4}\right)$ in the brain, liver, and kidney of the rats.

Results: After 1 day of an administration with $\mathrm{NiO}-\mathrm{NPs}$ or $\mathrm{CO}_{3} \mathrm{O}_{4}-\mathrm{NPs}$, at the dose levels of $0.5 \mathrm{and} 1.0 \mathrm{~g} / \mathrm{kg}$, remarkable elevations in malondialdehyde (MDA) levels, percentage of DNA damage (\%DNA), tail length (TL), and tail moment (TM), accompanied by marked reductions in the levels of zinc (Zn), glutathione (GSH) as well as the activities and expression levels of the superoxide dismutase (SOD) were recorded in all the studied groups, as compared to the controls. The changes in the levels of all the studied parameters were in a time- and dose-dependent manner. Excessive productions of the reactive oxygen species (ROS) associated with the genomic DNA fragmentation were observed in the experimental groups, as compared to the controls. However, in the groups administered with $\mathrm{NiO}-\mathrm{NPs}$ and $\mathrm{CO}_{3} \mathrm{O}_{4}$-NPs together, the alterations in all the studied parameters were improved as compared to those administered NiO-NPs or $\mathrm{CO}_{3} \mathrm{O}_{4}-\mathrm{NPs}$ solely.
\end{abstract}

Conclusion: The NiO-NPs and $\mathrm{CO}_{3} \mathrm{O}_{4}$-NPs antagonized each other leading to an alleviation of the genotoxicity induced by each of them.

Keywords: Cobalt oxide, Genotoxicity, Nanoparticles, Nickel oxide, Oxidative stress, Rats

\section{Background}

Nanoparticles (NPs), the particles with one of their dimensions at least less than $100 \mathrm{~nm}$, are extensively used in every field of our life (Morsy, Abou El-Ala, \& Ali, 2016b). Metal oxide nanoparticles (MNPs) including $\mathrm{Co}_{3} \mathrm{O}_{4}-\mathrm{NPs}$ and $\mathrm{NiO}-\mathrm{NP}_{\mathrm{S}}$ possess unique physical properties including higher activity, larger surface area to volume ratio, and higher absorption compared to their bulk materials (Biener et al., 2009). NiO-NPs are involved in many applications including batteries, sensors, and catalyzers (Magaye et al., 2016). $\mathrm{Co}_{3} \mathrm{O}_{4}$-NPs are applied in the fields of electronics, battery, and superconductor synthesis as well as used as a drug carrier (Sundar et al., 2017).

\footnotetext{
*Correspondence: Atef@Sci.Cu.Edu.Eg

'Physiology Division, Zoology Department, Faculty of Science, Cairo

University, Giza, Egypt

Full list of author information is available at the end of the article
}

Moreover, $\mathrm{Co}_{3} \mathrm{O}_{4}$-NPs are intensively used in many biomedical applications including imaging, cancer therapy, and gene therapy (Magaye, Zhao, Bowman, \& Ding, 2012). However, the wide application of these MNPs led to their release into the environment in various ways resulting in an increased human exposure to these NPs via inhalation, oral ingestion, and dermal contact (Kirkland et al., 2015). Upon exposure, NPs can penetrate cells more rapidly and provide unprecedented toxicological interactions with cell biomolecules (Jeon, Park, Rhee, \& Lee, 2010).

$\mathrm{NiO}$ showed relatively low toxicity as compared to the other Ni compounds (Zhao et al., 2009). However, several studies have evidenced that NiO-NPs caused cytotoxic and apoptotic effects in various mammalian cell lines (Lu et al., 2008; Ada et al., 2010 and Pietruska et al., 2011). Furthermore, NiO-NP-induced toxicity has been demonstrated in microorganisms such as bacteria 
(Baek \& An, 2011), algae (Gong et al., 2011), and plants (Faisal et al., 2013). Moreover, intratracheal instillation of NiO-NPs induced inflammation in the lungs of rats (Horie et al., 2011 and Morimoto et al., 2011). Likewise, acute oral administration of NiO-NPs-induced chromosomal aberration, micronuclei formation, and DNA damage were observed in rats (Dumala et al., 2017).

In vitro studies showed that $\mathrm{Co}_{3} \mathrm{O}_{4}$-NPs induced micronucleus and oxidative DNA damage (Alarifi et al., 2013; Cavallo et al., 2015 and Uboldi et al., 2015). However, limited studies investigated the genotoxicity and carcinogenicity of $\mathrm{Co}_{3} \mathrm{O}_{4}$-NPs in vivo. The study by Bucher et al. (1999) revealed that rats administered $\mathrm{Co}_{3} \mathrm{O}_{4}$ - NPs over 2 years induced benign bronchio-alveolar carcinoma, lung tumor, bronchio-alveolar adenomas, and adenocarcinomas. Moreover, oral administration of $\mathrm{Co}_{3} \mathrm{O}_{4}$-NPs resulted in genomic and mitochondrial DNA damage induction in mice (Mohamed \& Hussien, 2018).

Both NiO-NPs and $\mathrm{Co}_{3} \mathrm{O}_{4}$ - NPs are used together in mixed alloys to speed up their electrochemical activation (Schneiderová et al., 2017). Unfortunately, most of the previous studies were targeted to investigate the effects of individual NPs. Little is known about the interaction of $\mathrm{NiO}-\mathrm{NPs}$ and $\mathrm{Co}_{3} \mathrm{O}_{4}$-NPs on the molecular level. Therefore, the current study was undertaken to study the genotoxicity and oxidative stress induced by an acute oral administration of $\mathrm{Co}_{3} \mathrm{O}_{4}-\mathrm{NPs}$ or/and $\mathrm{NiO}-\mathrm{NPs}$ in male albino rats.

\section{Methods}

\section{Experimental design}

The animals were randomly separated into the seven groups with fifteen rats per each group as displayed in Table 1. The applied doses were chosen depending on a previous study by our work group (Ali, 2018).

At each time interval, five rats were selected from each group and were immediately sacrificed after euthanasia using an overdose of sodium pentobarbital $(150 \mathrm{mg} / \mathrm{kg})$. The rats were dissected immediately to take the brain, liver, and kidney. The tissues were kept in deep freeze at $-80^{\circ} \mathrm{C}$, after being weighted till further processing.

\section{Materials \\ Nanoparticles}

The studied NPs were purchased from Sigma Aldrich (Ward Hill, Massachusetts, USA). According to the manufacturing data sheets, the average particle sizes of the nano-sized $\mathrm{NiO}$ (black, 99.8\% pure) and $\mathrm{Co}_{3} \mathrm{O}_{4}$ (dark gray, $99.5 \%$ pure) were less than $50 \mathrm{~nm}$. Characterization was executed in a separate work to study the surface charge, X-ray diffraction pattern, and hydrodynamic diameter of these NPs (Ali, 2018).

\section{Dose preparation}

Stock solutions of the $\mathrm{NiO}-\mathrm{NPs}$ and $\mathrm{Co}_{3} \mathrm{O}_{4}$ - $\mathrm{NPs}$ were prepared by being suspended in $0.5 \%$ carboxymethyl cellulose (CMC). Immediately before the administration, NP suspensions were ultra-sonicated for $15 \mathrm{~min}$ using ultrasonic homogenizer (BioLogics, Inc., Manassas, VA, USA). Each dose had the volume of $2 \mathrm{ml}$ of NP suspension per $100 \mathrm{~g}$ of body weight.

\section{Animal model}

Healthy male Wistar rats, Rattus norvegicus, were obtained with an average body weight of $120 \mathrm{~g}$ from the National Research Center (NRC), Dokki, Giza, Egypt. Rats were acclimatized for 7 days in polyethylene cages at room temperature and subjected to normal $12 / 12 \mathrm{~h}$ light-dark cycle inside the animal house of Zoology Department, Faculty of Science, Cairo University. The rats were supplied with a standard rodent chow as well as a free access to water. The cages were cleaned day after day from feces and debris.

\section{Experimental procedures Measurement of lipid peroxide in tissues}

To estimate the levels of malondialdehyde (MDA) in the brain, liver, and kidney, small pieces from each tissue were homogenized in cold potassium phosphate buffer

Table 1 The experimental design of the study

\begin{tabular}{|c|c|c|c|c|c|c|c|}
\hline \multirow[t]{3}{*}{ Group } & \multirow{3}{*}{ Control } & \multicolumn{6}{|c|}{ Experimental groups } \\
\hline & & \multicolumn{2}{|c|}{ NiO-NPs alone } & \multicolumn{2}{|c|}{$\mathrm{CO}_{3} \mathrm{O}_{4}$-NPs alone } & \multicolumn{2}{|c|}{ Mixed groups } \\
\hline & & $\|$ & III & IV & V & $\overline{\mathrm{Vl}}$ & VII \\
\hline Sample size & 15 rats & 15 rats & 15 rats & 15 rats & 15 rats & 15 rats & 15 rats \\
\hline $0.5 \% \mathrm{CMC}$ & +++ & +++ & +++ & +++ & +++ & +++ & +++ \\
\hline $\mathrm{NiO}-\mathrm{NPS}$ & - & $0.5 \mathrm{~g} / \mathrm{kg}$ & $1.0 \mathrm{~g} / \mathrm{kg}$ & - & - & $0.25 \mathrm{~g} / \mathrm{kg}$ & $0.5 \mathrm{~g} / \mathrm{kg}$ \\
\hline $\mathrm{CO}_{3} \mathrm{O}_{4}-\mathrm{NPS}$ & - & - & - & $0.5 \mathrm{~g} / \mathrm{kg}$ & $1.0 \mathrm{~g} / \mathrm{kg}$ & $0.25 \mathrm{~g} / \mathrm{kg}$ & $0.5 \mathrm{~g} / \mathrm{kg}$ \\
\hline Route & Oral & Oral & Oral & Oral & Oral & Oral & Oral \\
\hline Frequency & Single & Single & Single & Single & Single & Single & Single \\
\hline Sampling time & \multicolumn{7}{|c|}{ After 1,7 , and 14 days of administration } \\
\hline
\end{tabular}


(50 mM, pH 7.5), and then was centrifuged for $15 \mathrm{~min}$ at speed of $4000 \mathrm{rpm}$. The levels of MDA were estimated in the resultant supernatant according to the technique described by Ohkawa, Ohishi, and Yagi (1979). The principle of this method depends on the reaction of the liberated MDA after lipid peroxidation of the cell membranes with thiobarbituric acid in acidic medium.

\section{Measurement of non-enzymatic and enzymatic antioxidants} A small piece from each organ was homogenized in a tube containing cold potassium phosphate buffer (50 $\mathrm{mM}, \mathrm{pH} 7.5)$ with $1 \mathrm{mM}$ EDTA. Then, the tubes were centrifugated for $15 \mathrm{~min}$ at a speed of $9000 \mathrm{rpm}$ at $4{ }^{\circ} \mathrm{C}$. The levels of glutathione (GSH) and activity of superoxide dismutase (SOD) were measured in the produced supernatant. The estimation of GSH was based on the reaction between GSH and 5,5'-dithiobis-2-nitrobenzoic acid (Beutler, Duron, \& Kelly, 1963) However, the method for determination of SOD was based on the ability of SOD to inhibit nitroblue tetrazolium dye (Nishikimi, Roa, \& Yogi, 1972).

\section{Quantification of the copper-zinc SOD expression level}

To determine the expression level of $\mathrm{Cu} / \mathrm{Zn}-\mathrm{SOD}$ in the brain, liver, and kidney of all rats, total RNA was firstly extracted from tissues using GeneJET RNA Purification Kit (Thermo Scientific, USA). DNase I (Thermo Scientific, USA) was applied to remove any residual DNA. Complementary DNA (cDNA) transcripts were synthesized from the purified RNA using Revert Aid First Strand cDNA synthesis kit (Thermo Scientific, USA). Then, real time-polymerase chain reaction (RT-PCR) was performed using the Step One Plus 7500 Fast system (Applied Biosystem 7500, Clinilab, Cairo, Egypt) to quantitatively detect SOD gene expression levels. A $12-\mu \mathrm{L}$ of the RT-PCR reaction mixture was prepared for each sample containing $2 \times$ SYBR Green master mix (Thermo Scientific, USA) and forward 5'-GGTG GTCCACGAGAAACAAG-3' and reverse CAAT CACCACAAGCCAAG-3' primers for $\mathrm{Cu} / \mathrm{Zn}$-SOD gene (Jiménez-Ortega, Cano, Cardinali, \& Esquifino, 2009). For amplification, RT-PCR reaction was initiated with initial denaturation at $95^{\circ} \mathrm{C}$ for $15 \mathrm{~min}$ then 35 cycles of denaturation at $95^{\circ} \mathrm{C}$ for $15 \mathrm{~s}$, annealing at $60^{\circ} \mathrm{C}$ for $30 \mathrm{~s}$, and extension at $72{ }^{\circ} \mathrm{C}$ for $1 \mathrm{~min}$ was done. The expression levels of the amplified $\mathrm{Cu} / \mathrm{Zn}$-SOD gene were standardized using the housekeeping gene GAPDH as a reference gene. GAPDH was amplified using the primer sequences forward 5' -AGGTGGAAGAATGGGAGTTG and reverse TCAAGAAGGTGGTGAAGCAG (Zhang et al., 2012). Results were interpreted and expression of $\mathrm{Cu} / \mathrm{Zn}$-SOD was determined using the comparative $\mathrm{Ct}$ (DDCt) and expressed as fold change in the expression level as compared to the untreated control level.

\section{Measurement of zinc levels in tissues}

The levels of $\mathrm{Zn}$ were measured in the brain, liver, and kidney of the experimental rats according to the method described by Demirbaş, (1999). In brief, tissues were washed with cold phosphate-buffered saline and approximately $0.5-1.5 \mathrm{~g}$ of tissues were digested using an acid mixture $\left(\mathrm{HNO}_{3}: \mathrm{HClO}_{4}=4: 1, \mathrm{v}: \mathrm{v}\right)$. Then, the volume of digest was completed to $25 \mathrm{ml}$ with demineralized water and $\mathrm{Zn}$ concentrations was measured using inductively coupled plasma mass spectrometry (ICP-MS, USA) against blanks and standard solutions.

\section{Estimation of DNA damage using alkaline comet assay}

The extent of DNA damage was measured in the brain, liver, and kidney of all the studied groups using alkaline comet assay (Tice et al., 2000). Small pieces of the desired tissue were gently homogenized into cold mincing solutions then mixed with $75 \mu \mathrm{l}$ of $0.5 \%$ low melting agarose. Each $10 \mu \mathrm{l}$ of cell suspension is containing about 10,000 cells. The cells were spread with agarose on a slide pre-dipped in normal $1 \%$ melting agarose and allowed to dry. Then, slides were incubated in cold lysis buffer $(2.5 \mathrm{M} \mathrm{NaCl}, 100 \mathrm{mM}$ EDTA, and $10 \mathrm{mM}$ Tris, $\mathrm{pH} 10$, with freshly added $10 \%$ DMSO and $1 \%$ Triton $\mathrm{X}-100$ ) at $4{ }^{\circ} \mathrm{C}$ in darkness for $24 \mathrm{~h}$. After lysis, slides were incubated for $20 \mathrm{~min}$ in a fresh alkaline buffer $(300$ $\mathrm{mM} \mathrm{NaOH}$ and $1 \mathrm{mM}$ EDTA, $\mathrm{pH}>13$ ), electrophoresed for $30 \mathrm{~min}$ at $25 \mathrm{~V}$ and $300 \mathrm{~mA}$. DNA was neutralized by dipping slides in 0.4 M Trizma base ( $\mathrm{pH} 7.5)$ and fixed in $100 \%$ cold ethanol. The slides were dried and stored at room temperature until they were scored. Before the imaging, slides were stained with ethidium bromide and 50 comet cells per animal were analyzed using a TriTek CometScore $^{\mathrm{Tm}}$ Freeware v1.5 scoring software. \%DNA in the tail, TL, and TM were used as indicators for DNA damage.

\section{Laddered DNA fragmentation assay}

Laddered DNA fragmentation technique was executed to assess the apoptotic DNA fragmentation in the studied tissues according to the protocol described by Sriram, Kanth, Kalishwaralal, and Gurunathan (2010). A small piece of each tissue was homogenized and lysed in Tris EDTA buffer containing $0.5 \%$ sodium dodecyl sulfate and RNase A. Then, samples were incubated at $37^{\circ}$ $\mathrm{C}$ for $1 \mathrm{~h}$ and proteinase $\mathrm{K}$ was added. Samples were incubated again overnight at $50{ }^{\circ} \mathrm{C}$. Genomic DNA was extracted by phenol extraction method and precipitated by ammonium acetate and isopropanol. Finally, $3 \mu \mathrm{g} / 15 \mu \mathrm{L}$ of the extracted DNA with $5 \mu \mathrm{L}$ of loading dye were electrophoresed in $1 \%$ agarose gel at $70 \mathrm{~V}$ then visualized using a UV transilluminator and photographed. 
Estimation of intracellular ROS generation

The production of ROS was estimated in the brain, liver, and kidney using the method described by Wang \& Joseph (1999) and Siddiqui et al. (2010). The technique depends on using 2,7-dichlorofluorescin diacetate (DCFH-DA) that enters the cell passively and reacts with ROS to form the highly fluorescent compound dichlorofluorescein (DCF). The DCFH-DA (20 mM) was added to the cell suspension and samples were incubated in dark for $30 \mathrm{~min}$ then visualized and imaged the cells using epi-fluorescent at $\times 20$ magnification.

\section{Statistical analysis}

Data were analyzed using Statistical Package of the Social Sciences; SPSS version 22 (copyrighted by IBM SPSS software, USA). Duncan and least significant difference (LSD) tests were utilized to estimate the similarities among all the experimental groups and significant differences between the experimental intervals. Regression analysis and Pearson's correlation coefficient were applied to study the relationships between the studied variables. Data is presented as a mean \pm standard error of mean (SEM).

\section{Results}

Effect of nanoparticles on lipid peroxidation and endogenous antioxidants

In Table 2, the levels of MDA and GSH of all the studied organs of all experimental rats throughout the experiments were displayed. In all organs of groups II to VII, the MDA levels were significantly higher than in group I at the first day. At most intervals, the MDA levels in organs of groups II and V were markedly lower than in groups III and IV, respectively. On the fourteenth day, the levels of MDA in most organs of all groups were markedly declined than at the first day and became similar to the controls, except in groups V and VI.

On contrary, at the first and seventh days, the GSH content of all tissues of all groups II to VII was significantly depleted, as compared to group I. GSH levels of organs of groups III and IV were remarkably lower than in groups II and $\mathrm{V}$, at most experimental periods. By the fourteenth day, most organs of groups II to VII exhibited marked elevations in the GSH content, as compared to the first day. GSH content was returned to the control values except in groups III and IV. In all the rats administered NiO-NPs or/and $\mathrm{Co}_{3} \mathrm{O}_{4}$-NPs, the MDA levels were negatively correlated with the levels of GSH in all organs (Table 4).

Table 2 The levels of malondialdehyde (MDA) and glutathione (GSH), after 1, 7, and 14 days in the brain, liver, and kidneys of control rats (I), and those administered $0.5 \mathrm{~g}$ and $1.0 \mathrm{~g}$ of NiO-NPs (II and III), $0.5 \mathrm{~g}$ and $1.0 \mathrm{~g} \mathrm{of} \mathrm{CO}_{3} \mathrm{O}_{4}-\mathrm{NPs}$ (IV and $V_{1}$ ) as well as mixtures of $\mathrm{NiO}-\mathrm{NPs}+\mathrm{CO}_{3} \mathrm{O}_{4}-\mathrm{NPs}(0.25 \mathrm{~g}+0.25 \mathrm{~g}$, VI) and $(0.5 \mathrm{~g}+0.5 \mathrm{~g}$, VII) per kilogram body weight, respectively

\begin{tabular}{|c|c|c|c|c|c|c|c|c|c|}
\hline \multirow[t]{2}{*}{ Parameter } & & \multirow{2}{*}{$\begin{array}{l}\text { Time } \\
\text { (days) }\end{array}$} & \multicolumn{7}{|c|}{ Experimental group } \\
\hline & & & I & $\|$ & III & IV & V & $\mathrm{Vl}$ & $\mathrm{VII}$ \\
\hline \multirow{9}{*}{$\begin{array}{l}\text { MDA (nmol/g } \\
\text { tissue) }\end{array}$} & \multirow[t]{3}{*}{ Brain } & 1 & $5.11 \pm 0.19^{a}$ & $6.54 \pm 0.04^{c}$ & $7.31 \pm 0.31^{d}$ & $7.11 \pm 0.25^{d}$ & $6.49 \pm 0.09^{c}$ & $6.43 \pm 0.24^{b}$ & $6.25 \pm 0.23^{b}$ \\
\hline & & 7 & $5.16 \pm 0.11^{\mathrm{a}}$ & $6.40 \pm 0.19^{b c}$ & $7.23 \pm 0.31^{c}$ & $6.83 \pm 0.10^{b c}$ & $6.51 \pm 0.39^{b c}$ & $6.37 \pm 0.33^{b c}$ & $6.07 \pm 0.33^{b}$ \\
\hline & & 14 & $5.18 \pm 0.14^{\mathrm{a}}$ & $5.75 \pm 0.10^{a b^{* \#}}$ & $6.74 \pm 0.35^{c^{*}}$ & $6.18 \pm 0.01^{\mathrm{bc} * \#}$ & $5.69 \pm 0.32^{\mathrm{ab}}$ & $5.49 \pm 0.10^{\mathrm{a}^{* \#}}$ & $5.49 \pm 0.12^{\mathrm{a}^{*}}$ \\
\hline & \multirow[t]{3}{*}{ Liver } & 1 & $6.27 \pm 0.10^{\mathrm{a}}$ & $7.50 \pm 0.15^{c}$ & $8.48 \pm 0.11^{d}$ & $7.99 \pm 0.05^{d}$ & $7.43 \pm 0.13^{c}$ & $7.33 \pm 0.31^{b}$ & $7.09 \pm 0.30^{b}$ \\
\hline & & 7 & $6.29 \pm 0.10^{\mathrm{a}}$ & $6.93 \pm 0.29^{b c}$ & $7.15 \pm 0.07^{\mathrm{bc}}$ & $7.23 \pm 0.06^{c^{*}}$ & $6.57 \pm 0.04^{a b^{*}}$ & $6.73 \pm 0.25^{\mathrm{ab}}$ & $6.64 \pm 0.28^{\mathrm{ab}}$ \\
\hline & & 14 & $6.31 \pm 0.19^{\mathrm{ab}}$ & $6.49 \pm 0.01^{b c^{*}}$ & $6.90 \pm 0.02^{c^{* \#}}$ & $7.02 \pm 0.19^{c^{*}}$ & $6.45 \pm 0.09^{b^{*}}$ & $5.91 \pm 0.23^{\mathrm{a}^{*}}$ & $6.07 \pm 0.18^{a b^{*}}$ \\
\hline & \multirow[t]{3}{*}{ Kidney } & 1 & $5.83 \pm 0.29^{a}$ & $7.50 \pm 0.06^{c}$ & $8.10 \pm 0.14^{d}$ & $7.99 \pm 0.14^{d}$ & $7.50 \pm 0.14^{c}$ & $6.75 \pm 0.24^{b}$ & $6.98 \pm 0.30^{b}$ \\
\hline & & 7 & $5.94 \pm 0.31^{a}$ & $6.56 \pm 0.13^{\mathrm{a}^{*}}$ & $7.51 \pm 0.13^{b^{*}}$ & $7.48 \pm 0.09^{b^{*}}$ & $6.77 \pm 0.18^{a b^{*}}$ & $6.65 \pm 0.33^{\mathrm{ab}}$ & $6.74 \pm 0.50^{a b}$ \\
\hline & & 14 & $5.91 \pm 0.24^{\mathrm{a}}$ & $6.33 \pm 0.05^{\mathrm{a}^{*}}$ & $7.18 \pm 0.14^{\mathrm{b}^{*}}$ & $7.23 \pm 0.09^{b^{*}}$ & $6.27 \pm 0.28^{\mathrm{a}^{*}}$ & $5.91 \pm 0.23^{\mathrm{a}^{*}}$ & $5.76 \pm 0.26^{a^{*}}$ \\
\hline \multirow{9}{*}{$\begin{array}{l}\text { GSH (mg/g } \\
\text { issue) }\end{array}$} & \multirow[t]{3}{*}{ Brain } & 1 & $25.35 \pm 0.99^{c}$ & $21.66 \pm 0.48^{b}$ & $20.02 \pm 0.20^{a}$ & $18.82 \pm 0.22^{a}$ & $21.63 \pm 0.52^{b}$ & $21.66 \pm 0.92^{b}$ & $22.00 \pm 0.94^{b}$ \\
\hline & & 7 & $25.40 \pm 1.43^{b}$ & $22.85 \pm 0.49^{a}$ & $20.23 \pm 0.39^{a}$ & $20.71 \pm 0.20^{\mathrm{a}^{*}}$ & $22.61 \pm 0.96^{\mathrm{a}^{*}}$ & $22.33 \pm 0.95^{\mathrm{a}}$ & $22.70 \pm 0.76^{a}$ \\
\hline & & 14 & $25.60 \pm 1.33^{c}$ & $25.24 \pm 0.63^{c^{* \# \#}}$ & $21.46 \pm 0.42^{\mathrm{a}^{* \#}}$ & $22.40 \pm 0.13^{a b^{* \#}}$ & $24.40 \pm 0.51^{b c^{*}}$ & $24.24 \pm 0.87^{b c}$ & $25.45 \pm 1.08^{c^{*}}$ \\
\hline & \multirow[t]{3}{*}{ Liver } & 1 & $47.65 \pm 0.70^{d}$ & $40.88 \pm 0.88^{c}$ & $33.57 \pm 1.43^{\mathrm{a}}$ & $34.98 \pm 0.65^{b}$ & $39.62 \pm 0.47^{c}$ & $37.38 \pm 1.59^{c}$ & $39.00 \pm 1.66^{c}$ \\
\hline & & 7 & $47.70 \pm 1.02^{c}$ & $42.46 \pm 0.87^{b}$ & $39.27 \pm 0.36^{a b^{*}}$ & $37.86 \pm 0.85^{a^{*}}$ & $42.17 \pm 0.25^{b^{*}}$ & $40.00 \pm 1.70^{\mathrm{ab}}$ & $40.22 \pm 1.71^{\mathrm{ab}}$ \\
\hline & & 14 & $48.10 \pm 0.40^{b}$ & $47.86 \pm 0.28^{b^{* \#}}$ & $45.53 \pm 0.40^{\mathrm{a}^{*} \#}$ & $44.20 \pm 0.13^{\mathrm{a}^{*} \#}$ & $46.40 \pm 0.41^{a b^{* \#}}$ & $47.42 \pm 2.02^{\mathrm{ab*} \#}$ & $48.03 \pm 2.04^{b^{*}}$ \\
\hline & \multirow[t]{3}{*}{ Kidney } & 1 & $53.98 \pm 2.07^{d}$ & $38.00 \pm 0.15^{b}$ & $34.26 \pm 0.14^{a}$ & $39.37 \pm 0.57^{b}$ & $40.22 \pm 1.71^{c}$ & $41.66 \pm 1.77^{c}$ & $43.60 \pm 1.85^{c}$ \\
\hline & & 7 & $53.80 \pm 1.46^{e}$ & $44.88 \pm 0.31^{b c^{*}}$ & $41.48 \pm 0.51^{a b^{*}}$ & $40.69 \pm 0.29^{a^{*}}$ & $44.91 \pm 0.27^{b c^{*}}$ & $47.16 \pm 1.86^{\mathrm{cd}}$ & $48.90 \pm 2.08^{d}$ \\
\hline & & 14 & $54.10 \pm 1.71^{b}$ & $51.93 \pm 0.27^{b^{* \#}}$ & $44.26 \pm 0.36^{\mathrm{a}^{*} \#}$ & $46.00 \pm 0.19^{a^{*} \#}$ & $50.27 \pm 0.66^{b^{* \#}}$ & $51.11 \pm 2.17^{b^{*}}$ & $52.79 \pm 2.25^{\mathrm{b}^{*}}$ \\
\hline
\end{tabular}

Data is represented as mean \pm standard error of mean

In the same row, values marked with the different superscript letters are statistically differed $(P<0.05)$, while those with similar ones are insignificantly differed $(P>0.05)$

*, \#: significant differences (at $P<0.05$ ), as compared to the values at the first and seventh day, respectively 
The activities of SOD and expression levels of SOD gene in all tissues of experimental rats were demonstrated in Table 3. At most intervals, SOD activities and gene expression levels of tested organs in all experimental groups were markedly inhibited, as compared to group I. In groups II and V, SOD activity and SOD gene expression levels in all tissues, at most times, were markedly higher than in groups III and IV, respectively. By the fourteenth day, rats of groups II to V showed significant elevations in all organ activities of SOD and SOD gene expression levels toward the control value. In most organs of groups VI and VII, by the fourteenth day, SOD activity and SOD gene expression levels became similar to group I. Negative relationships were recorded between the activity of SOD and MDA levels, in all organs of rats treated with $\mathrm{NiO}-\mathrm{NPs}$ or/and $\mathrm{Co}_{3} \mathrm{O}_{4}$ - $\mathrm{NPs}$ (Table 4). Significant positive correlations were observed between the expression levels of SOD gene and the SOD activities in all tissues of all rats administered NiO-NPs or/and $\mathrm{Co}_{3} \mathrm{O}_{4}$-NPs (Table 5).

\section{Effect of nanoparticles on zinc levels in tissues}

The concentrations of $\mathrm{Zn}$ in all tissues of the experimental rats, throughout the experiments, were shown in Table 3. In most organs of groups II to VII, Zn levels were markedly lower than in group I, at all periods. By the fourteenth

Table 3 The activities of superoxide dismutase (SOD), expression levels of SOD gene, and levels of zinc (Zn), after 1, 7, and 14 days, in the brain, liver, and kidneys of control rats (I), and those administered $0.5 \mathrm{~g}$ and $1.0 \mathrm{~g}$ of NiO-NPs (II and III), $0.5 \mathrm{~g}$ and $1.0 \mathrm{~g}$ of $\mathrm{CO}_{3} \mathrm{O}_{4}-\mathrm{NPs}$ (IV and $\mathrm{V}$ ) as well as mixtures of NiO-NPs $+\mathrm{CO}_{3} \mathrm{O}_{4}-\mathrm{NPs}(0.25 \mathrm{~g}+0.25 \mathrm{~g}$, VI) and $(0.5 \mathrm{~g}+0.5 \mathrm{~g}$, VII) per kg body weight, respectively

\begin{tabular}{|c|c|c|c|c|c|c|c|c|c|}
\hline \multirow[t]{2}{*}{ Parameter } & & \multirow{2}{*}{$\begin{array}{l}\text { Time } \\
\text { (days) }\end{array}$} & \multicolumn{7}{|c|}{ Experimental group } \\
\hline & & & I & $\|$ & III & IV & V & $\mathrm{Vl}$ & VII \\
\hline \multirow{9}{*}{$\begin{array}{l}\text { SOD activity (U/g } \\
\text { tissue) }\end{array}$} & \multirow[t]{3}{*}{ Brain } & 1 & $2.47 \pm 0.11^{\mathrm{e}}$ & $1.40 \pm 0.03^{b}$ & $1.02 \pm 0.03^{\mathrm{a}}$ & $1.15 \pm 0.01^{a}$ & $1.46 \pm 0.01^{b}$ & $1.58 \pm 0.07^{c}$ & $1.93 \pm 0.03^{d}$ \\
\hline & & 7 & $2.48 \pm 0.13^{e}$ & $1.69 \pm 0.07^{\mathrm{bc}}{ }^{*}$ & $1.44 \pm 0.01^{\mathrm{a}^{*}}$ & $1.52 \pm 0.05^{\mathrm{ab}^{*}}$ & $1.72 \pm 0.01^{b c^{*}}$ & $1.85 \pm 0.01^{c^{*}}$ & $2.15 \pm 0.09^{\mathrm{d}^{*}}$ \\
\hline & & 14 & $2.46 \pm 0.06^{f}$ & $2.20 \pm 0.05^{\mathrm{cd}^{*} \#}$ & $1.78 \pm 0.04^{\mathrm{a}^{*} \#}$ & $2.07 \pm 0.04^{\mathrm{b}^{*} \#}$ & $2.11 \pm 0.01^{b c^{* \#}}$ & $2.23 \pm 0.01^{\mathrm{d}^{* \#}}$ & $2.32 \pm 0.02^{\mathrm{e}^{*}}$ \\
\hline & \multirow[t]{3}{*}{ Liver } & 1 & $0.53 \pm 0.01^{e}$ & $0.33 \pm 0.01^{b}$ & $0.24 \pm 0.01^{a}$ & $0.34 \pm 0.01^{b}$ & $0.38 \pm 0.02^{c}$ & $0.37 \pm 0.02^{c}$ & $0.40 \pm 0.01^{d}$ \\
\hline & & 7 & $0.54 \pm 0.01^{\mathrm{e}}$ & $0.41 \pm 0.01^{1^{*}}$ & $0.33 \pm 0.01^{1^{*}}$ & $0.37 \pm 0.01^{b}$ & $0.40 \pm 0.01^{c}$ & $0.41 \pm 0.01^{*^{*}}$ & $0.46 \pm 0.01^{\mathrm{d}^{*}}$ \\
\hline & & 14 & $0.55 \pm 0.01^{c}$ & $0.50 \pm 0.01^{b_{* \#}}$ & $0.43 \pm 0.01^{\mathrm{a}^{* \#}}$ & $0.44 \pm 0.02^{\mathrm{a}^{* \#}}$ & $0.52 \pm 0.02^{\mathrm{bc} * \#}$ & $0.52 \pm 0.01^{b c^{*} \#}$ & $0.55 \pm 0.02^{c^{* \# \#}}$ \\
\hline & \multirow[t]{3}{*}{ Kidney } & 1 & $2.52 \pm 0.05^{e}$ & $1.58 \pm 0.04^{b}$ & $1.14 \pm 0.01^{a}$ & $1.49 \pm 0.03^{b}$ & $1.75 \pm 0.04^{c}$ & $1.83 \pm 0.03^{c}$ & $1.97 \pm 0.01^{d}$ \\
\hline & & 7 & $2.59 \pm 0.09^{e}$ & $1.74 \pm 0.02^{\mathrm{b}^{*}}$ & $1.57 \pm 0.02^{\mathrm{a}^{*}}$ & $1.64 \pm 0.02^{\mathrm{ab}}$ & $2.00 \pm 0.06^{\mathrm{Cd}^{*}}$ & $1.95 \pm 0.01^{c^{*}}$ & $2.13 \pm 0.03^{\mathrm{d}^{*}}$ \\
\hline & & 14 & $2.47 \pm 0.06^{c}$ & $2.14 \pm 0.01^{b^{*} \#}$ & $1.91 \pm 0.03^{\mathrm{a}^{* \#}}$ & $2.15 \pm 0.09^{\mathrm{b}_{* \#}}$ & $2.16 \pm 0.01^{b^{* \# \#}}$ & $2.24 \pm 0.01^{b^{* \#}}$ & $2.46 \pm 0.20^{c^{*} \#}$ \\
\hline \multirow{9}{*}{$\begin{array}{l}\text { SOD gene } \\
\text { (expression level) }\end{array}$} & \multirow[t]{3}{*}{ Brain } & 1 & $1.00 \pm 0.00^{f}$ & $0.53 \pm 0.01^{b}$ & $0.49 \pm 0.01^{\mathrm{a}}$ & $0.48 \pm 0.01^{a}$ & $0.55 \pm 0.01^{c}$ & $0.59 \pm 0.01^{d}$ & $0.62 \pm 0.01^{e}$ \\
\hline & & 7 & $1.00 \pm 0.00^{f}$ & $0.57 \pm 0.01^{b^{*}}$ & $0.53 \pm 0.02^{\mathrm{a}^{*}}$ & $0.54 \pm 0.01^{\mathrm{ab}^{*}}$ & $0.64 \pm 0.01^{c^{*}}$ & $0.69 \pm 0.01^{\mathrm{d}^{*}}$ & $0.76 \pm 0.01^{\mathrm{e}^{*}}$ \\
\hline & & 14 & $1.00 \pm 0.00^{f}$ & $0.67 \pm 0.01^{\mathrm{b} * \#}$ & $0.64 \pm 0.01^{a^{*} \#}$ & $0.67 \pm 0.01^{\mathrm{b} * \#}$ & $0.79 \pm 0.01^{* \#}$ & $0.85 \pm 0.01^{d^{* \#}}$ & $0.89 \pm 0.01^{\mathrm{e}^{* \#}}$ \\
\hline & \multirow[t]{3}{*}{ Liver } & 1 & $1.00 \pm 0.00^{c}$ & $0.61 \pm 0.02^{b}$ & $0.51 \pm 0.01^{\mathrm{a}}$ & $0.59 \pm 0.01^{b}$ & $0.60 \pm 0.02^{b}$ & $0.54 \pm 0.01^{\mathrm{ab}}$ & $0.61 \pm 0.01^{b}$ \\
\hline & & 7 & $1.00 \pm 0.00^{c}$ & $0.74 \pm 0.02^{b^{*}}$ & $0.65 \pm 0.01^{\mathrm{a}^{*}}$ & $0.69 \pm 0.02^{2^{*}}$ & $0.76 \pm 0.02^{b^{*}}$ & $0.75 \pm 0.01^{\mathrm{b}^{*}}$ & $0.75 \pm 0.01^{b^{*}}$ \\
\hline & & 14 & $1.00 \pm 0.00^{d}$ & $0.81 \pm 0.02^{\mathrm{b}^{* \#}}$ & $0.72 \pm 0.01^{a^{*} \#}$ & $0.72 \pm 0.04^{2^{*}}$ & $0.82 \pm 0.01^{b^{*}}$ & $0.89 \pm 0.01^{\mathrm{d}^{*} \#}$ & $0.96 \pm 0.01^{\mathrm{d}^{*} \#}$ \\
\hline & \multirow[t]{3}{*}{ Kidney } & 1 & $1.00 \pm 0.00^{\mathrm{e}}$ & $0.35 \pm 0.03^{b}$ & $0.16 \pm 0.01^{a}$ & $0.33 \pm 0.01^{b}$ & $0.53 \pm 0.02^{c d}$ & $0.50 \pm 0.01^{c}$ & $0.57 \pm 0.02^{d}$ \\
\hline & & 7 & $1.00 \pm 0.00^{d}$ & $0.47 \pm 0.04^{\mathrm{b}^{*}}$ & $0.31 \pm 0.02^{\mathrm{a}^{*}}$ & $0.37 \pm 0.01^{\mathrm{a}^{*}}$ & $0.64 \pm 0.01^{1^{*}}$ & $0.61 \pm 0.03^{c^{*}}$ & $0.68 \pm 0.04^{c}$ \\
\hline & & 14 & $1.00 \pm 0.00^{d}$ & $0.65 \pm 0.01^{b^{* \#}}$ & $0.48 \pm 0.07^{\mathrm{a}^{* \#}}$ & $0.64 \pm 0.02^{\mathrm{b}^{* \#}}$ & $0.81 \pm 0.03^{*^{* \#}}$ & $0.99 \pm 0.03^{\mathrm{d}^{* \#}}$ & $0.99 \pm 0.04^{\mathrm{d}^{\mathrm{*} \#}}$ \\
\hline \multirow{9}{*}{$\begin{array}{l}\text { Zn levels ( } \mu \mathrm{g} / \mathrm{g} \\
\text { tissue) }\end{array}$} & \multirow[t]{3}{*}{ Brain } & 1 & $18.85 \pm 0.80^{d}$ & $10.60 \pm 0.16^{b c}$ & $7.18 \pm 0.31^{a}$ & $9.65 \pm 0.41^{b}$ & $10.78 \pm 0.36^{c}$ & $10.10 \pm 0.39^{b}$ & $11.23 \pm 0.39^{c}$ \\
\hline & & 7 & $18.96 \pm 0.81^{d}$ & $14.50 \pm 0.13^{b c^{*}}$ & $12.20 \pm 0.33^{\mathrm{a}^{*}}$ & $12.80 \pm 0.24^{\mathrm{a}^{*}}$ & $13.13 \pm 0.36^{b^{*}}$ & $14.26 \pm 0.44^{b c^{*}}$ & $14.69 \pm 0.62^{2^{*}}$ \\
\hline & & 14 & $18.75 \pm 0.80^{d}$ & $16.10 \pm 0.22^{b c^{* \#}}$ & $13.86 \pm 0.11^{a^{* \#}}$ & $15.18 \pm 0.26^{\mathrm{ab}^{* \#}}$ & $15.20 \pm 0.19^{a b^{* \#}}$ & $16.20 \pm 0.69^{b c^{* \# \#}}$ & $17.63 \pm 0.75^{\mathrm{cd}^{*} \#}$ \\
\hline & \multirow[t]{3}{*}{ Liver } & 1 & $31.29 \pm 1.33^{d}$ & $25.22 \pm 0.46^{b}$ & $19.09 \pm 0.81^{a}$ & $19.95 \pm 0.43^{a}$ & $24.55 \pm 0.50^{b}$ & $24.90 \pm 0.41^{b}$ & $26.67 \pm 0.21^{c}$ \\
\hline & & 7 & $31.43 \pm 1.34^{c}$ & $26.90 \pm 1.14^{b}$ & $21.31 \pm 0.91^{a}$ & $22.80 \pm 0.14^{\mathrm{a}^{*}}$ & $27.23 \pm 0.23^{b^{*}}$ & $27.93 \pm 1.05^{b^{*}}$ & $28.14 \pm 0.49^{b}$ \\
\hline & & 14 & $31.21 \pm 1.33^{b}$ & $29.29 \pm 1.04^{a b^{*}}$ & $26.21 \pm 0.51^{a^{* \#}}$ & $26.51 \pm 1.02^{\mathrm{a}^{* \#}}$ & $29.31 \pm 0.33^{a^{a b^{* \#}}}$ & $28.64 \pm 1.22^{\mathrm{ab}^{*}}$ & $31.50 \pm 1.34^{b^{* \#}}$ \\
\hline & \multirow[t]{3}{*}{ Kidney } & 1 & $23.63 \pm 1.01^{e}$ & $14.46 \pm 0.62^{b}$ & $13.39 \pm 0.57^{a}$ & $14.35 \pm 0.61^{a b}$ & $17.10 \pm 0.73^{c d}$ & $16.28 \pm 0.69^{b c}$ & $18.70 \pm 0.80^{d}$ \\
\hline & & 7 & $23.75 \pm 1.01^{d}$ & $18.73 \pm 0.80^{c^{*}}$ & $14.85 \pm 0.63^{a}$ & $15.94 \pm 0.68^{a b}$ & $17.96 \pm 0.76^{b c}$ & $18.03 \pm 0.35^{b c}$ & $19.80 \pm 0.84^{c}$ \\
\hline & & 14 & $23.68 \pm 1.01^{c}$ & $21.20 \pm 0.90^{\mathrm{bc} * \#}$ & $16.60 \pm 0.71^{\mathrm{a}^{*}}$ & $20.46 \pm 0.17^{b_{* \#}}$ & $22.73 \pm 0.24^{b c^{* \#}}$ & $23.90 \pm 0.92^{C^{* \# \#}}$ & $23.38 \pm 0.99^{c^{* \#}}$ \\
\hline
\end{tabular}

Data is represented as mean \pm standard error of mean. In the same row, values marked with the different superscript letters are statistically differed $(P<0.05)$, while those with similar ones are insignificantly differed $(P>0.05)$

*, \#: significant differences (at $P<0.05$ ), as compared to the values at the first and seventh days, respectively 


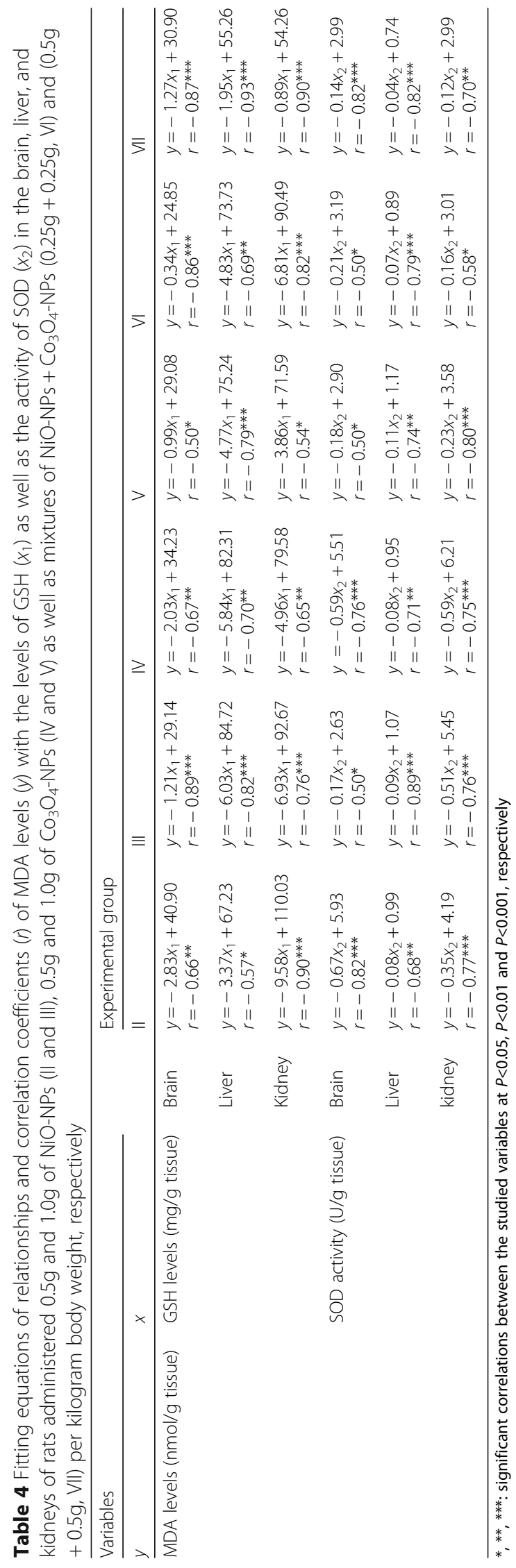


Table 5 Fitting equations and correlation coefficients $(r)$ of SOD activity $(y)$ with the levels of $\mathrm{Zn}\left(x_{1}\right)$ as well as the expression levels

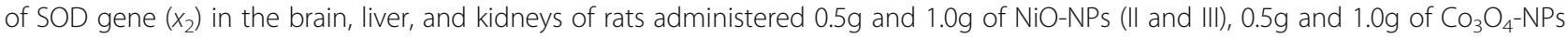
(IV and V), as well as mixtures of NiO-NPs $+\mathrm{CO}_{3} \mathrm{O}_{4}-\mathrm{NPs}(0.25 \mathrm{~g}+0.25 \mathrm{~g}, \mathrm{VI})$ and $(0.5 \mathrm{~g}+0.5 \mathrm{~g}$, VII) per kilogram body weight, respectively

\begin{tabular}{|c|c|c|c|c|c|c|c|c|}
\hline \multicolumn{3}{|l|}{ Variables } & \multicolumn{6}{|c|}{ Experimental group } \\
\hline$y$ & $x$ & & $\|$ & III & IV & V & $\mathrm{Vl}$ & $\mathrm{VII}$ \\
\hline \multirow[t]{6}{*}{$\begin{array}{l}\text { SOD activity } \\
\text { (U/g tissue) }\end{array}$} & $\begin{array}{l}\text { Zn levels } \\
\text { ( } \mathrm{g} / \mathrm{g} \text { tissue) }\end{array}$ & Brain & $\begin{array}{l}y=0.13 x_{1}-0.01 \\
r=+0.87^{* * *}\end{array}$ & $\begin{array}{l}y=0.10 x_{1}+0.28 \\
r=+0.94^{* * *}\end{array}$ & $\begin{array}{l}y=0.15 x_{1}-0.33 \\
r=+0.93^{* * *}\end{array}$ & $\begin{array}{l}y=0.13 x_{1}+0.08 \\
r=+0.93^{* * *}\end{array}$ & $\begin{array}{l}y=0.09 x_{1}+0.69 \\
r=+0.88^{* * *}\end{array}$ & $\begin{array}{l}y=0.06 x_{1}+1.28 \\
r=+0.88^{* * *}\end{array}$ \\
\hline & & Liver & $\begin{array}{l}y=0.02 x_{1}-0.09 \\
r=+0.68^{* *}\end{array}$ & $\begin{array}{l}y=0.02 x_{1}-0.10 \\
r=+0.85^{* * *}\end{array}$ & $\begin{array}{l}y=0.01 x_{1}+0.12 \\
r=+0.65^{* *}\end{array}$ & $\begin{array}{l}y=0.02 x_{1}-0.20 \\
r=+0.69^{* *}\end{array}$ & $\begin{array}{l}y=0.01 x_{1}+0.08 \\
r=+0.50^{*}\end{array}$ & $\begin{array}{l}y=0.02 x_{1}-0.22 \\
r=+0.90^{* * *}\end{array}$ \\
\hline & & Kidney & $\begin{array}{l}y=0.06 x_{1}+0.69 \\
r=+0.81^{* * *}\end{array}$ & $\begin{array}{l}y=0.13 x_{1}-0.40 \\
r=+0.75^{* * *}\end{array}$ & $\begin{array}{l}y=0.10 x_{1}+0.12 \\
r=+0.89^{*}\end{array}$ & $\begin{array}{l}y=0.04 x_{1}+1.17 \\
r=+0.61^{*}\end{array}$ & $\begin{array}{l}y=0.05 x_{1}+1.08 \\
r=+0.96^{* * *}\end{array}$ & $\begin{array}{l}y=0.06 x+0.93 \\
r=+0.78^{* * *}\end{array}$ \\
\hline & $\begin{array}{l}\text { SOD gene } \\
\text { (expression level) }\end{array}$ & Brain & $\begin{array}{l}y=5.15 x_{2}-1.26 \\
r=+0.94^{* * *}\end{array}$ & $\begin{array}{l}y=4.02 x_{2}-0.80 \\
r=+0.89^{* * *}\end{array}$ & $\begin{array}{l}y=4.56 x_{2}-0.98 \\
r=+0.94^{* * *}\end{array}$ & $\begin{array}{l}y=2.64 x_{2}+0.02 \\
r=+0.99^{* * *}\end{array}$ & $\begin{array}{l}y=2.27 x_{2}+0.28 \\
r=+0.91^{* * *}\end{array}$ & $\begin{array}{l}y=1.33 x_{2}+1.13 \\
r=+0.79^{* * *}\end{array}$ \\
\hline & & Liver & $\begin{array}{l}y=0.67 x-0.07 \\
r=+0.89^{* * *}\end{array}$ & $\begin{array}{l}y=0.84 x_{2}-0.19 \\
r=+0.96^{* * *}\end{array}$ & $\begin{array}{l}y=0.49 x_{2}+0.06 \\
r=+0.68^{* *}\end{array}$ & $\begin{array}{l}y=0.44 x_{2}+0.11 \\
r=+0.62^{*}\end{array}$ & $\begin{array}{l}y=0.39 x_{2}+0.15 \\
r=+0.82^{* * *}\end{array}$ & $\begin{array}{l}y=0.42 x_{2}+0.15 \\
r=+0.86^{* * *}\end{array}$ \\
\hline & & Kidney & $\begin{array}{l}y=1.52 x_{2}+1.07 \\
r=+0.84^{* * *}\end{array}$ & $\begin{array}{l}y=1.73 x_{2}+0.99 \\
r=+0.84^{* * *}\end{array}$ & $\begin{array}{l}y=2.07 x_{2}+0.84 \\
r=+0.94^{* * *}\end{array}$ & $\begin{array}{l}y=1.18 x_{2}+1.20 \\
r=+0.76^{* * *}\end{array}$ & $\begin{array}{l}y=0.79 x_{2}+1.46 \\
r=+0.95^{* * *}\end{array}$ & $\begin{array}{l}y=1.00 x_{2}+1.44 \\
r=+0.92^{* * *}\end{array}$ \\
\hline
\end{tabular}

***, ***: significant correlations between the studied variables at $P<0.05, P<0.01$ and $P<0.001$, respectively

day, Zn levels in all tissues of all groups were significantly increased, as compared to the first day, and reached control levels except in brain of groups II and V as well as all organs of groups III and IV. In all organs of rats administered $\mathrm{NiO}-\mathrm{NPs}$ or/and $\mathrm{Co}_{3} \mathrm{O}_{4}$-NPs, direct relationships were reported between the activities of SOD and the levels of $\mathrm{Zn}$ (Table 5).

\section{Effect of nanoparticles on comet parameters}

The comet assay results of all the experimental groups were clarified in Table 6. In all organs of groups II to VII, the \%DNA damage, TL and TM, were markedly higher than in group I, at most durations. By the fourteenth day, \%DNA damage, TL, and TM in tested organs of all groups were significantly declined, as compared to the first day. In all organs of groups III and IV, all comet parameters were mostly higher than those of groups II and $\mathrm{V}$, respectively.

\section{Effect of nanoparticles on the DNA fragmentation}

The electrophoresed pattern of genomic DNA was obtained from the brain, hepatic, and renal tissues of all rats (Fig. 1). In consistence with the comet assay results, by the first and seventh days, the degree of DNA fragmentation in the liver and kidney of all groups from II to VII were more obvious than in the brain, as compared to the corresponding controls. By the fourteenth day, the degree of DNA damage was declined in most tissues of the studied groups.

\section{Effect of nanoparticles on the reactive oxygen species production}

In Fig. 2, the results of ROS generation in the studied organs of all groups were presented. As compared to group I, the fluorescence microscopic images all organs of groups II to VII revealed excessive productions of intracellular ROS, at all intervals, as represented by the high intensity of fluorescence.

\section{Discussion}

The present study represents a continuation of a recent work in which the median lethal doses of the NiO-NPs or/and $\mathrm{Co}_{3} \mathrm{O}_{4}$-NPs as well as the accumulation patterns and toxicokinetics of their metal ions were estimated (Ali, 2018). The objective of the current work was to evaluate the genotoxicity and oxidative stress induced by $\mathrm{NiO}-\mathrm{NPs}$ or/and $\mathrm{Co}_{3} \mathrm{O}_{4}$-NPs in the brain, liver, and kidney of male albino rats. All the alterations in the present study were in consistence with the accumulation pattern of NiO-NPs and $\mathrm{Co}_{3} \mathrm{O}_{4}$-NPs, in our recent study (Ali, 2018).

The present data revealed remarkable elevations of \%DNA, TL, and TM in all organs of rats administered NiO-NPs or $\mathrm{Co}_{3} \mathrm{O}_{4}$-NPs solely. Single- and double-stranded breaks were evident in the genomic DNA after intake of NPs (Morsy et al., 2016a). Similarly, several previous studies reported DNA damage following exposure to NiO-NPs (Horie et al., 2011; Morimoto et al., 2011 and Dumala et al., 2017) and $\mathrm{Co}_{3} \mathrm{O}_{4}$-NPs (Alarifi et al., 2013; Uboldi et al., 2015 and Mohamed \& Hussien, 2018). Due to their high surface area and subsequent increased reactivity, NPs can induce the production of ROS (Liu, Xu, Zhang, Ren, \& Yang, 2010). Therefore, disturbances in DNA strand can be linked to the excessive generation of ROS (Rowe, Degtyareva, \& Doetsch, 2008 and Kang, So, Simons, Spitz, \& Ouchi, 2012). This was confirmed by the fluorescence microscopic images of the brain, liver, and kidney of the rats treated with $\mathrm{NiO}-\mathrm{NPs}$ or $\mathrm{Co}_{3} \mathrm{O}_{4}$ - NPs which demonstrated an overproduction of the intracellular ROS, in the 
Table 6 The percentage of DNA damage (\%DNA), tail length (TL), and tail moment (TM), after 1, 7, and 14 days in the brain, liver,

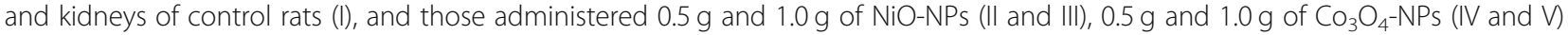
as well as mixtures of $\mathrm{NiO}-\mathrm{NPs}+\mathrm{CO}_{3} \mathrm{O}_{4}$-NPs $(0.25 \mathrm{~g}+0.25 \mathrm{~g}, \mathrm{Vl})$ and $(0.5 \mathrm{~g}+0.5 \mathrm{~g}$, VII) per kilogram body weight, respectively

\begin{tabular}{|c|c|c|c|c|c|c|c|c|c|}
\hline \multirow[t]{2}{*}{ Parameter } & & \multirow{2}{*}{$\begin{array}{l}\text { Time } \\
\text { (days) }\end{array}$} & \multicolumn{7}{|c|}{ Experimental group } \\
\hline & & & I & $\|$ & III & IV & V & $\mathrm{Vl}$ & VII \\
\hline \multirow[t]{9}{*}{ \%DNA damage } & Brain & 1 & $19.15 \pm 0.26^{\mathrm{a}}$ & $27.82 \pm 0.41^{\mathrm{e}}$ & $30.21 \pm 0.29^{f}$ & $26.01 \pm 0.49^{d}$ & $24.12 \pm 0.42^{c}$ & $22.64 \pm 0.15^{b}$ & $22.35 \pm 0.17^{b}$ \\
\hline & & 7 & $19.58 \pm 0.53^{\mathrm{a}}$ & $24.65 \pm 0.14^{c^{*}}$ & $27.35 \pm 0.07^{\mathrm{d}^{*}}$ & $24.52 \pm 0.11^{c^{*}}$ & $22.52 \pm 0.43^{b^{*}}$ & $22.21 \pm 0.39^{b}$ & $22.05 \pm 0.19^{b}$ \\
\hline & & 14 & $19.41 \pm 1.48^{\mathrm{a}}$ & $22.58 \pm 0.14^{b^{* \#}}$ & $25.25 \pm 0.47^{c^{* \#}}$ & $22.64 \pm 0.36^{b^{* \#}}$ & $20.43 \pm 0.18^{\mathrm{a}^{* \#}}$ & $20.61 \pm 0.15^{\mathrm{a}^{* \#}}$ & $20.31 \pm 0.26^{\mathrm{a}^{* \#}}$ \\
\hline & Liver & 1 & $20.47 \pm 0.41^{a}$ & $27.67 \pm 0.32^{d}$ & $30.75 \pm 0.43^{e}$ & $27.38 \pm 0.07^{d}$ & $26.51 \pm 0.20^{c}$ & $24.37 \pm 0.17^{b}$ & $24.26 \pm 0.59^{b}$ \\
\hline & & 7 & $20.46 \pm 0.33^{a}$ & $26.03 \pm 0.23^{\mathrm{e}^{*}}$ & $28.32 \pm 0.67^{f^{*}}$ & $24.28 \pm 0.08^{\mathrm{d}^{*}}$ & $22.65 \pm 0.20^{c^{*}}$ & $22.07 \pm 0.33^{b^{*}}$ & $21.36 \pm 0.24^{b^{*}}$ \\
\hline & & 14 & $20.12 \pm 0.52^{\mathrm{a}}$ & $21.58 \pm 0.14^{b^{* \#}}$ & $25.67 \pm 0.80^{c^{* \#}}$ & $22.33 \pm 0.17^{b^{* \#}}$ & $21.44 \pm 0.25^{a b^{*} \#}$ & $20.28 \pm 0.64^{\mathrm{a}^{* \#}}$ & $20.16 \pm 0.58^{\mathrm{a}^{*}}$ \\
\hline & Kidney & 1 & $20.76 \pm 0.40^{a}$ & $28.36 \pm 0.04^{e}$ & $31.20 \pm 0.25^{f}$ & $28.50 \pm 0.22^{e}$ & $26.25 \pm 0.06^{d}$ & $25.37 \pm 0.23^{c}$ & $23.96 \pm 0.27^{b}$ \\
\hline & & 7 & $21.26 \pm 0.33^{\mathrm{a}}$ & $27.15 \pm 0.28^{\mathrm{d}^{*}}$ & $29.57 \pm 0.62^{e^{*}}$ & $27.34 \pm 0.34^{d^{*}}$ & $24.51 \pm 0.04^{c^{*}}$ & $24.06 \pm 0.08^{c^{*}}$ & $22.44 \pm 0.37^{b^{*}}$ \\
\hline & & 14 & $21.27 \pm 0.64^{a}$ & $25.12 \pm 0.41^{c^{* \#}}$ & $26.30 \pm 0.17^{d^{* \#}}$ & $24.40 \pm 0.18^{c^{*} \#}$ & $22.51 \pm 0.25^{b^{* \#}}$ & $22.91 \pm 0.39^{b^{* \#}}$ & $21.16 \pm 0.02^{\mathrm{a}^{* \#}}$ \\
\hline \multirow[t]{9}{*}{$T L$} & Brain & 1 & $1.01 \pm 0.12^{\mathrm{a}}$ & $1.75 \pm 0.05^{c}$ & $1.99 \pm 0.03^{d}$ & $1.71 \pm 0.01^{c}$ & $1.69 \pm 0.01^{c}$ & $1.64 \pm 0.01^{c}$ & $1.56 \pm 0.03^{b}$ \\
\hline & & 7 & $1.03 \pm 0.11^{\mathrm{a}}$ & $1.55 \pm 0.02^{c^{*}}$ & $1.78 \pm 0.01^{\mathrm{d}^{*}}$ & $1.54 \pm 0.03^{c^{*}}$ & $1.47 \pm 0.01^{c^{*}}$ & $1.48 \pm 0.01^{c^{*}}$ & $1.36 \pm 0.01^{\mathrm{b}^{*}}$ \\
\hline & & 14 & $0.99 \pm 0.08^{\mathrm{a}}$ & $1.41 \pm 0.01^{c^{* \#}}$ & $1.53 \pm 0.01^{\mathrm{d}^{*} \#}$ & $1.42 \pm 0.02^{c^{*} \#}$ & $1.27 \pm 0.01^{b^{* \#} \#}$ & $1.25 \pm 0.03^{b^{* \#}}$ & $1.20 \pm 0.01^{\mathrm{b} \# \#}$ \\
\hline & Liver & 1 & $1.25 \pm 0.02^{\mathrm{a}}$ & $1.81 \pm 0.01^{c}$ & $2.07 \pm 0.11^{d}$ & $1.95 \pm 0.03^{d}$ & $1.73 \pm 0.02^{c}$ & $1.66 \pm 0.03^{c}$ & $1.54 \pm 0.02^{b}$ \\
\hline & & 7 & $1.25 \pm 0.01^{\mathrm{a}}$ & $1.72 \pm 0.02^{\mathrm{d}^{*}}$ & $1.85 \pm 0.02^{\mathrm{e}^{*}}$ & $1.85 \pm 0.01^{\mathrm{e}^{*}}$ & $1.52 \pm 0.01^{c^{*}}$ & $1.52 \pm 0.01^{c^{*}}$ & $1.35 \pm 0.02^{b^{*}}$ \\
\hline & & 14 & $1.26 \pm 0.04^{a}$ & $1.56 \pm 0.02^{c^{* \#}}$ & $1.71 \pm 0.01^{\mathrm{d}^{*}}$ & $1.46 \pm 0.01^{b^{* \#}}$ & $1.25 \pm 0.01^{\mathrm{a}^{* \#}}$ & $1.28 \pm 0.01^{\mathrm{a}^{* \#}}$ & $1.24 \pm 0.02^{\mathrm{a}^{* \#}}$ \\
\hline & Kidney & 1 & $1.10 \pm 0.05^{\mathrm{a}}$ & $1.77 \pm 0.01^{d}$ & $1.97 \pm 0.02^{\mathrm{e}}$ & $1.83 \pm 0.02^{d}$ & $1.63 \pm 0.03^{c}$ & $1.57 \pm 0.01^{c}$ & $1.42 \pm 0.01^{b}$ \\
\hline & & 7 & $1.08 \pm 0.01^{a}$ & $1.62 \pm 0.02^{\mathrm{e}^{*}}$ & $1.83 \pm 0.01^{* *}$ & $1.66 \pm 0.02^{\mathrm{e}^{*}}$ & $1.54 \pm 0.03^{d}$ & $1.40 \pm 0.01^{c^{*}}$ & $1.28 \pm 0.01^{b^{*}}$ \\
\hline & & 14 & $1.11 \pm 0.07^{a}$ & $1.38 \pm 0.01^{c^{* \# \#}}$ & $1.62 \pm 0.01^{e^{* \#}}$ & $1.53 \pm 0.01^{\mathrm{d}^{*} \#}$ & $1.37 \pm 0.02^{c^{* \#}}$ & $1.23 \pm 0.02^{b^{* \#}}$ & $1.17 \pm 0.02^{\mathrm{a}^{*} \#}$ \\
\hline \multirow[t]{9}{*}{ TM } & Brain & 1 & $0.19 \pm 0.02^{\mathrm{a}}$ & $0.49 \pm 0.01^{d}$ & $0.60 \pm 0.01^{\mathrm{e}}$ & $0.47 \pm 0.01^{d}$ & $0.39 \pm 0.01^{c}$ & $0.35 \pm 0.01^{c}$ & $0.33 \pm 0.01^{b}$ \\
\hline & & 7 & $0.20 \pm 0.03^{a}$ & $0.38 \pm 0.01^{\mathrm{d}^{*}}$ & $0.49 \pm 0.01^{\mathrm{e}^{*}}$ & $0.38 \pm 0.01^{\mathrm{d}^{*}}$ & $0.33 \pm 0.02^{c^{*}}$ & $0.26 \pm 0.01^{b^{*}}$ & $0.23 \pm 0.01^{a^{*}}$ \\
\hline & & 14 & $0.19 \pm 0.03^{\mathrm{a}}$ & $0.32 \pm 0.01^{c^{* \#}}$ & $0.39 \pm 0.01^{d^{*} \#}$ & $0.32 \pm 0.01^{c^{* \#}}$ & $0.26 \pm 0.01^{b^{* \#}}$ & $0.22 \pm 0.01^{a^{* \#}}$ & $0.21 \pm 0.01^{a^{*}}$ \\
\hline & Liver & 1 & $0.26 \pm 0.01^{a}$ & $0.50 \pm 0.01^{d}$ & $0.64 \pm 0.04^{e}$ & $0.51 \pm 0.01^{d}$ & $0.44 \pm 0.01^{c}$ & $0.44 \pm 0.01^{c}$ & $0.39 \pm 0.01^{b}$ \\
\hline & & 7 & $0.26 \pm 0.01^{a}$ & $0.45 \pm 0.01^{\mathrm{d}^{*}}$ & $0.52 \pm 0.01^{\mathrm{e}^{*}}$ & $0.45 \pm 0.01^{\mathrm{d}^{*}}$ & $0.32 \pm 0.01^{b^{*}}$ & $0.38 \pm 0.01^{c^{*}}$ & $0.32 \pm 0.01^{b^{*}}$ \\
\hline & & 14 & $0.25 \pm 0.01^{a}$ & $0.34 \pm 0.01^{b^{*} \#}$ & $0.44 \pm 0.02^{c^{*}}$ & $0.33 \pm 0.01^{b^{* \#}}$ & $0.26 \pm 0.01^{\mathrm{a}^{* \#}}$ & $0.27 \pm 0.01^{\mathrm{a}^{* \#}}$ & $0.26 \pm 0.02^{a^{*} \#}$ \\
\hline & Kidney & 1 & $0.23 \pm 0.01^{a}$ & $0.50 \pm 0.01^{e}$ & $0.61 \pm 0.01^{f}$ & $0.52 \pm 0.01^{e}$ & $0.43 \pm 0.01^{d}$ & $0.40 \pm 0.01^{c}$ & $0.34 \pm 0.01^{b}$ \\
\hline & & 7 & $0.23 \pm 0.01^{a}$ & $0.44 \pm 0.01^{\mathrm{e}^{*}}$ & $0.54 \pm 0.01^{f^{*}}$ & $0.45 \pm 0.01^{\mathrm{e}^{*}}$ & $0.38 \pm 0.01^{\mathrm{d}^{*}}$ & $0.34 \pm 0.01^{c^{*}}$ & $0.29 \pm 0.01^{b^{*}}$ \\
\hline & & 14 & $0.24 \pm 0.02^{\mathrm{a}}$ & $0.35 \pm 0.01^{c^{* \#}}$ & $0.43 \pm 0.01^{\mathrm{e}^{* \#}}$ & $0.37 \pm 0.01^{\mathrm{d}^{* \#}}$ & $0.31 \pm 0.01^{b_{* \#}}$ & $0.28 \pm 0.01^{b_{* \#}}$ & $0.25 \pm 0.01^{a^{*} \#}$ \\
\hline
\end{tabular}

Data is represented as mean \pm standard error of mean. In the same row, values marked with the different superscript letters are statistically differed $(P<0.05)$, while those with similar ones are insignificantly differed $(P>0.05)$

* \#: significant differences (at $P<0.05$ ), as compared to the values at the first and seventh days, respectively

current results. Moreover, the single- and double-stranded breaks of DNA can eventually trigger apoptosis (Green, 2011). This can explain the observed apoptotic DNA damages demonstrated by the electrophoresed pattern of genomic DNA in all tested tissues of rats administered $\mathrm{NiO}-\mathrm{NPs}$ or $\mathrm{Co}_{3} \mathrm{O}_{4}$-NPs, individually. In the present data, the kidney and liver exhibited substantial DNA fragmentations as compared to the brain. This can be attributed to their ability to accumulate more NPs for further elimination (Morsy et al., 2016b).

Lipid peroxidation (LPO) represents the chief biomarker of the oxidative damage (Abdel Wahab, 2012). Once LPO is initiated, a chain of free radical-mediated reactions proceeds to produce several toxic byproducts such as the MDA (Prabhakar et al., 2012). The present study revealed remarkable elevations in MDA levels accompanied with significant depletions in the GSH content and SOD activity in the studied organs of rats administered $\mathrm{NiO}-\mathrm{NPs}$ (with increasing dose) or $\mathrm{Co}_{3} \mathrm{O}_{4}$-NPs (with decreasing dose). Such disturbances in the endogenous homeostasis can be ascribed to direct action of accumulated NPs or their ions (Morsy, Abou El-Ala, \& Ali, 2016a). In the same line, Ali (2018) reported that in all tissues of rats, the levels of accumulated $\mathrm{Ni}^{2+}$ were positively correlated with the doses of NiO-NPs whereas the accumulated 


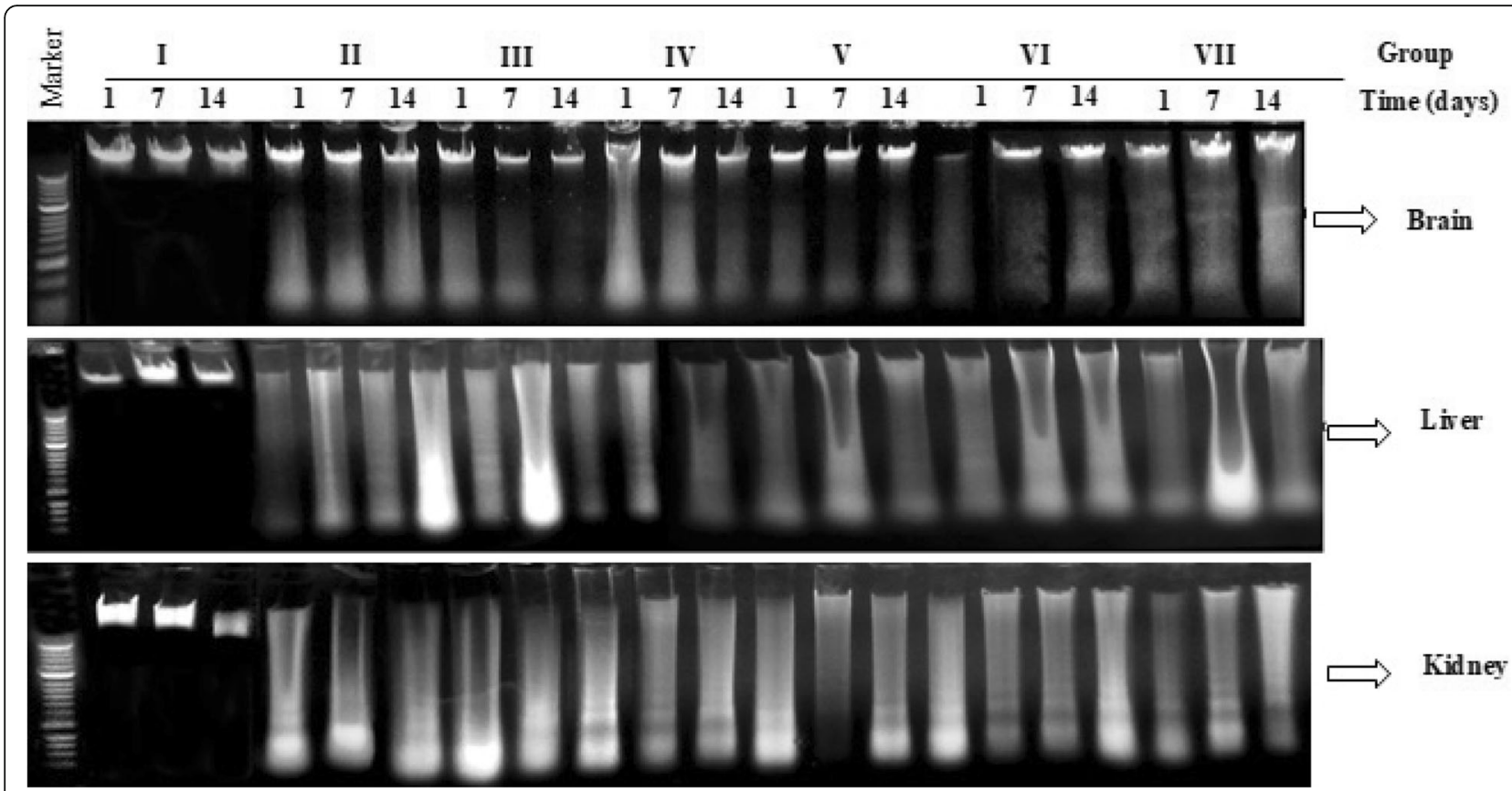

Fig. 1 Gel electrophoresis pattern of the genomic DNA extracted from the brain, liver, and kidney of control rats (I), and those administered $0.5 \mathrm{~g}$ and $1.0 \mathrm{~g}$ of NiO-NPs (II and III), $0.5 \mathrm{~g}$ and $1.0 \mathrm{~g}$ of $\mathrm{CO}_{3} \mathrm{O}_{4}-\mathrm{NPs}\left(\mathrm{IV}\right.$ and $\mathrm{V}$ ), as well as mixtures of NiO-NPs $+\mathrm{CO}_{3} \mathrm{O}_{4}-\mathrm{NPs}(0.25 \mathrm{~g}+0.25 \mathrm{~g}, \mathrm{VI})$ and $(0.5 \mathrm{~g}$ $+0.5 \mathrm{~g}$, VII) per kg body weight, respectively

levels of $\mathrm{Co}^{2+}$ were negatively correlated with administered doses of $\mathrm{Co}_{3} \mathrm{O}_{4}$-NPs. This was attributed to the high tendency of $\mathrm{Co}_{3} \mathrm{O}_{4}$ - $\mathrm{NPs}$, in biological fluids, more than NiO-NPs leading to reduced ionization of the former. Additionally, the present findings can be linked to the increased production of ROS that strongly attacks the double bonds of the polyunsaturated fatty acids giving rise to several products including the MDA (Sánchez-Iglesias et al., 2009). Moreover, MDA molecules can attack and combine with many functional groups on macromolecules including proteins, lipoproteins, and even DNA generating further DNA damage (Marnett, 2002), leading to the destruction of endogenous antioxidants including GSH and SOD which are mainly proteins. This was ensured, in the present results, by the inverse relationships of MDA levels with the GSH content and SOD activity. In addition, $\mathrm{Zn}$ is an essential element for the action of the cytoplasmic SOD (El-Khawaga \& El-Sayed, 2012) as well as for the biosynthesis of GSH (Cortese, Suschek, Wetzel, Kroncke, \& Kolb-Bachofen, 2008 and Li et al. 2010) Accordingly, the reduced activity of SOD and levels of GSH may be also attributed to the ability of NPs to interfere with Zn availability, as confirmed by the reduced tissue levels of $\mathrm{Zn}$, in the present study. This was supported by the recorded direct relationships between $\mathrm{Zn}$ levels and SOD ativities, in the present study. Furthermore, the reduced activity of SOD can be related to the capability of NiO-NPs and $\mathrm{Co}_{3} \mathrm{O}_{4}$-NPs to reduce the expression levels of the $\mathrm{Cu} / \mathrm{Zn}$-SOD gene, as shown in the present data. On the contrary, by increasing the experimental time, GSH level and SOD activity were markedly increased concurrently with the increment of $\mathrm{Zn}$ and expression of $\mathrm{Cu} / \mathrm{Zn}$-SOD levels in tissues. Moreover, the remarkable depletion in the GSH levels as well as SOD activity can allow the increased production of ROS and subsequently an increased MDA levels.

Comet parameters in tested organs of rats administered $\mathrm{NiO}-\mathrm{NPs}$ in combination with $\mathrm{Co}_{3} \mathrm{O}_{4}$ - $\mathrm{NPs}$ were markedly lower than in groups administered NiO-NPs or $\mathrm{Co}_{3} \mathrm{O}_{4}$-NPs solely. This reflects that the concurrent administration of these NPs caused recurrence of normal DNA integrity leading to reduced genotoxicity. This was ensured by the observed partial DNA damages in electrophoresed tissues of the mixed groups. The reduced DNA damage can be linked to the recorded reduction in MDA levels and increased levels of GSH in tissues of these rats. Moreover, the relapse of the normal integrity of DNA can cause the reported remarkable elevations in the $\mathrm{Cu} / \mathrm{Zn}$-SOD expression levels and consequently elevated SOD activity. The recorded reduction of MDA levels may be also attributed to the ability of these NPs to diminish the accumulation whereas to enhance the elimination of each other from tissues (Ali, 2018). This can be achieved via competition between their ions on the same receptors on tissues (Vijver, Peijnenburg, \& De Snoo, 2010). 


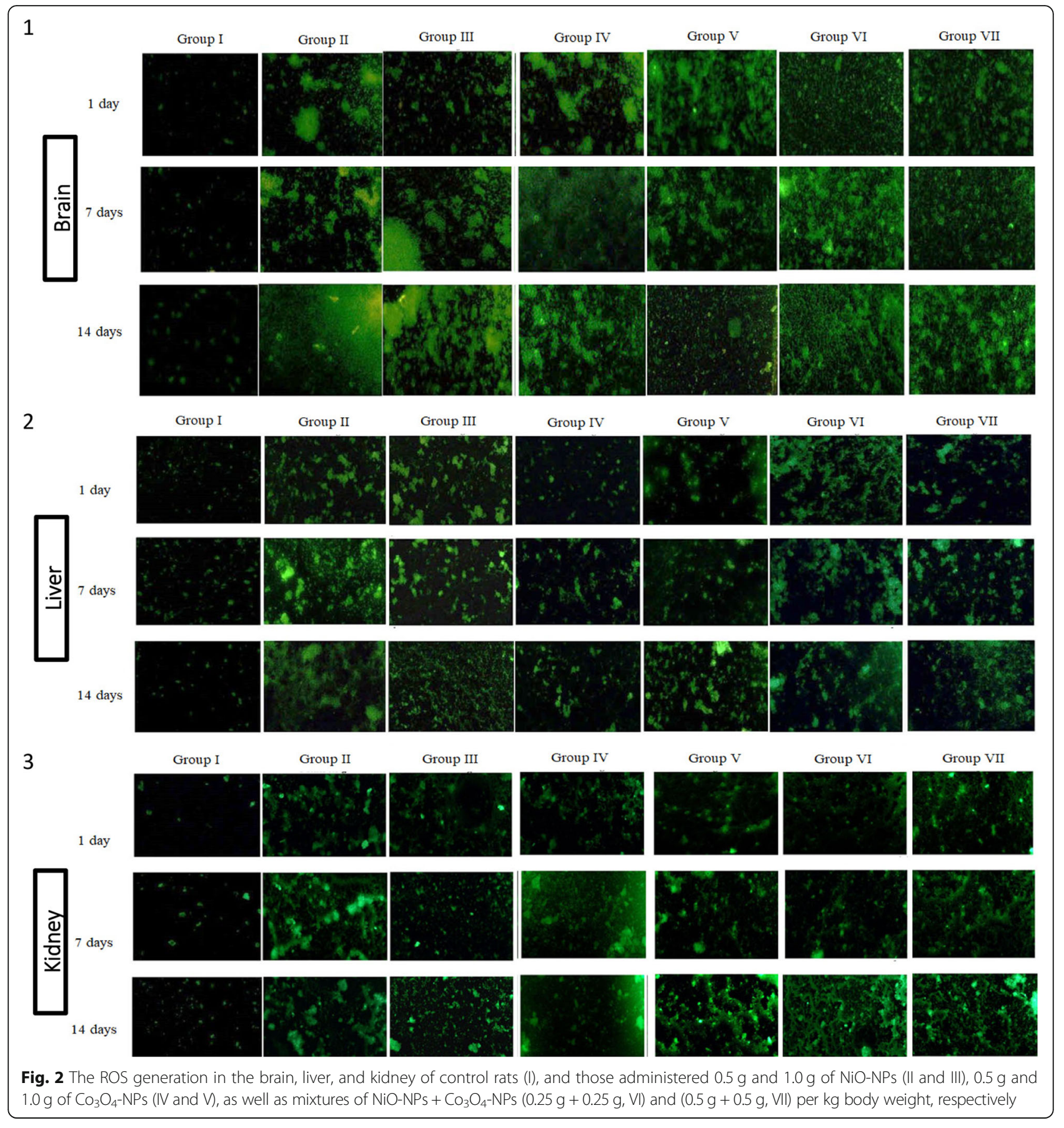

\section{Conclusion}

Firstly, single oral administration of NiO-NPs or $\mathrm{Co}_{3} \mathrm{O}_{4}$-NPs caused DNA strand breaks, apoptotic damage, and ROS excessive generation that markedly increased the MDA levels whereas it significantly reduced the levels of $\mathrm{Zn}, \mathrm{GSH}$, and activity of SOD in the brain, liver, and kidney tissues. Secondly, the alterations in all the studied parameters in tissues of rats administered $\mathrm{NiO}-\mathrm{NPs}$ or $\mathrm{Co}_{3} \mathrm{O}_{4}$-NPs were in time- and dosedependent manner. Thirdly, the administration of
$\mathrm{NiO}-\mathrm{NPs}$ together with $\mathrm{Co}_{3} \mathrm{O}_{4}$-NPs substantially alleviated the genotoxicity and the oxidative stress induced by each of the NPs.

\section{Abbreviations}

\%DNA: Percentage DNA; $\mathrm{CO}_{3} \mathrm{O}_{4}$ : Cobalt oxide; GSH: Glutathione; LPO: Lipid peroxidation; MDA: Malondialdehyde; NiO: Nickel oxide; NPs: Nanoparticles; SOD: Superoxide dismutase; TL: Tail length; TM: Tail moment; Zn: Zinc

\section{Acknowledgements}

We acknowledge the continuous support of our department and our colleagues. 


\section{Funding}

Funding was provided by Faculty of Science, Cairo University.

\section{Availability of data and materials}

All data are available upon request.

\section{Authors' contributions}

AAA designed the experiment and contributed in animal handling, experimental procedures, biochemical analysis, statistical analysis, and manuscript writing. MHRH contributed to the molecular techniques. Both authors read and approved the final manuscript.

\section{Ethics approval}

All the applied procedures were approved by Cairo University- Institutional Animal Care and Use Committee (CU-IACUC), Giza, Egypt. The protocol approval number was CU///F/97/17 at November 2017. The animal handling was in accordance to the international guidelines of the laboratory animal care and use.

\section{Consent for publication}

The data provided here is original.

\section{Competing interests}

The authors declare that they have no competing interests.

\section{Publisher's Note}

Springer Nature remains neutral with regard to jurisdictional claims in published maps and institutional affiliations.

\section{Author details}

'Physiology Division, Zoology Department, Faculty of Science, Cairo University, Giza, Egypt. ${ }^{2}$ Cell Biology, Genetics and Histology Division, Zoology Department, Cairo University, Giza, Egypt.

Received: 3 December 2018 Accepted: 20 December 2018 Published online: 09 January 2019

\section{References}

Abdel Wahab, W. M. (2012). AlCl -induced toxicity and oxidative stress in liver of male rats: protection by melatonin. Life Science Journal, 9(4), 1173-1182.

Ada, K., Turk, M., Oguztuzun, S., Kilic, M., Demirel, M., Tandogan, N., ... Latif, O. (2010). Cytotoxicity and apoptotic effects of nickel oxide nanoparticles in cultured HeLa cells. Folia Histochemica et Cytobiologica, 48(4), 524-529.

Alarifi, S., Ali, D., Al Omar Suliman, Y., Ahamed, M., Siddiqui, M. A., \& Al-Khedhairy, A. A. (2013). Oxidative stress contributes to cobalt oxide nanoparticlesinduced cytotoxicity and DNA damage in human hepatocarcinoma cells. International Journal of Nanomedicine, 8, 189-199.

Ali, A. A. (2018). Bioaccumulation and toxicokinetics of the orally administered nanosized nickel and cobalt (II, III) oxides in male albino rats. Egyptian Journal of Zoology, (In Press).

Baek, Y. W., \& An, Y. J. (2011). Microbial toxicity of metal oxide nanoparticles $\left(\mathrm{CuO}, \mathrm{NiO}, \mathrm{ZnO}\right.$, and $\left.\mathrm{Sb}_{2} \mathrm{O}_{3}\right)$ to Escherichia coli, Bacillus subtilis, and Streptococcus aureus. Science of the Total Environment, 409(8), 1603-1608.

Beutler, E., Duron, O., \& Kelly, M. B. (1963). Improved method for the determination of blood glutathione. Journal of Laboratory and Clinical Medicine, 61, 882-888.

Biener, J., Wittstock, A., Baumann, T., Weissmüller, J., Bäumer, M., \& Hamza, A. (2009). Surface chemistry in nanoscale materials. Materials, 2(4), 2404-2428.

Bucher, J. R., Hailey, J. R., Roycroft, J. R., Haseman, J. K., Sills, R. C., Grumbein, S. L., ... Chou, B. J. (1999). Inhalation toxicity and carcinogenicity studies of cobalt sulfate. Toxicological Sciences, 49, 56-67.

Cavallo, D., Ciervo, A., Fresegna, A. M., Maiello, R., Tassone, P., Buresti, G., ... Ursini, C. L. (2015). Investigation on cobalt-oxide nanoparticles cyto-genotoxicity and inflammatory response in two types of respiratory cells. Journal of Applied Toxicology, 35(10), 1102-1113.

Cortese, M. M., Suschek, C. V., Wetzel, W., Kroncke, K. D., \& Kolb-Bachofen, V. (2008). Zinc protects endothelial cells from hydrogen peroxide via Nrf2dependent stimulation of glutathione biosynthesis. Free Radical Biology and Medicine, 44, 2002-2012.

Demirbass, A. (1999). Proximate and heavy metal composition in chicken meat and tissues. Food Chemistry, 67, 27-31.
Dumala, N., Mangalampalli, B., Chinde, S., Kumari, S. I., Mahoob, M., Rahman, M. F., \& Grover, P. (2017). Genotoxicity study of nickel oxide nanoparticles in female Wister rats after acute oral exposure. Mutagenesis, 32, 417-427.

El-Khawaga, O. Y., \& El-Sayed, I. H. (2012). Evaluation of trace elements and antioxidants in pre and post hemodialysis of chronic renal failure patients. International Journal of Natural Sciences, 3(3), 617-620.

Faisal, M., Saquib, Q., Alatar, A. A., Al-Khedhairy, A. A., Hegazy, A. K., \& Musarrat, J. (2013). Phytotoxic hazards of NiO-nanoparticles in tomato: a study on mechanism of cell death. Journal of Hazardous Materials, 250, 318-332.

Gong, N., Shao, K., Feng, W., Lin, Z., Liang, C., \& Sun, Y. (2011). Biotoxicity of nickel oxide nanoparticles and bio-remediation by microalgae Chlorella vulgaris. Chemosphere, 83(4), 510-516.

Green, D. (2011). Means to an end: apoptosis and other cell death mechanisms. Cold Spring Harbor: Cold Spring Harbor Laboratory Press ISBN 978-0-87969888-1.

Horie, M., Fukui, H., Nishio, K., Endoh, S., Kato, H., Fujita, K., ... Kinugasa, S. (2011). Evaluation of acute oxidative stress induced by $\mathrm{NiO}$ nanoparticles in vivo and in vitro. Journal of Occupational Health, 53(2), 64-74.

Jeon, Y. M., Park, S. K., Rhee, S. K., \& Lee, M. Y. (2010). Proteomic profiling of the differentially expressed proteins by $\mathrm{TiO}_{2}$ nanoparticles in mouse kidney. Molecular and Cellular Toxicology, 6, 419-425.

Jiménez-Ortega, V., Cano, P., Cardinali, D. P., \& Esquifino, A. I. (2009). 24-hour variation in gene expression of redox pathway enzymes in rat hypothalamus: effect of melatonin treatment. Redox Reports, 14(3), 132-138.

Kang, M. A., So, E. Y., Simons, A. L., Spitz, D. R., \& Ouchi, T. (2012). DNA damage induces reactive oxygen species generation through the H2AX-Nox1/Rac1 pathway. Cell Death and Disease, 3(1), e249. https://doi.org/10.1038/cddis. 2011.134.

Kirkland, D., Brock, T., Haddouk, H., Hargeaves, V., Lloyd, M., Mc Garry, S., ... Sokolowski, A. (2015). New investigations into the genotoxicity of cobalt compounds and their impact on overall assessment of genotoxic risk. Regulatory Toxicology and Pharmacology, 73(1), 311-338.

Liu, S., Xu, L., Zhang, T., Ren, G., \& Yang, Z. (2010). Oxidative stress and apoptosis induced by nanosized titanium dioxide in PC12 cells. Toxicology, 267(1-3), 172-177.

Lu, S., Duffin, R., Poland, C., Daly, P., Murphy, F., Drost, E., ... Donaldson, K. (2008). Efficacy of simple short-term in vitro assays for predicting the potential of metal oxide nanoparticles to cause pulmonary inflammation. Environmental Health Perspectives, 117(2), 241-247.

Magaye, R., Gu, Y., Wang, Y., Su, H., Zhou, Q., Mao, G., ... Zhao, J. (2016). In vitro and in vivo evaluation of the toxicities induced by metallic nickel nano and fine particles. Journal of Molecular Histology, 47(3), 273-286.

Magaye, R., Zhao, J., Bowman, L., \& Ding, M. (2012). Genotoxicity and carcinogenicity of cobalt-, nickel-and copper-based nanoparticles. Experimental and Therapeutic Medicine, 4(4), 551-561.

Marnett, L. J. (2002). Lipid peroxidation-DNA damage by malondialdehyde. Mutation Research, 424, 83-95.

Mohamed, H. R. H., \& Hussien, N. A. (2018). Amelioration of cobalt oxide nanoparticles induced genomic and mitochondrial DNA damage and oxidative stress by omega-3 co-administration in mice. Caryologia, 71(4), 357364

Morimoto, Y., Hirohashi, M., Ogami, A., Oyabu, T., Myojo, T., Hashiba, M., .. Tanaka, I. (2011). Pulmonary toxicity following an intratracheal instillation of nickel oxide nanoparticle agglomerates. Journal of Occupational Health, 53(4), 293-295.

Morsy, G. M., Abou El-Ala, K. S., \& Ali, A. A. (2016a). Studies on fate and toxicity of nanoalumina in male albino rats: oxidative stress in the brain, liver and kidney. Toxicology and industrial health, 32(2), 200-214.

Morsy, G. M., El-Ala, K. S. A., \& Ali, A. A. (2016b). Studies on fate and toxicity of nanoalumina in male albino rats: lethality, bioaccumulation and genotoxicity. Toxicology and industrial health, 32(2), 344-359.

Nishikimi, M., Roa, N. A., \& Yogi, K. (1972). Measurement of superoxide dismutase. Biochemical and Biophysical Research Communications, 46, 849-854.

Ohkawa, H., Ohishi, W., \& Yagi, K. (1979). Assay for lipid peroxides in animal tissues by thiobarbituric acid reaction. Analytical Biochemistry, 95, 351-358.

Pietruska, J. R., Liu, X., Smith, A., McNeil, K., Weston, P., Zhitkovich, A., ... Kane, A. B. (2011). Bioavailability, intracellular mobilization of nickel, and HIF-1a activation in human lung epithelial cells exposed to metallic nickel and nickel oxide nanoparticles. Toxicological Sciences, 124(1), 138-148.

Prabhakar, P. V., Reddy, U. A., Singh, S. P., Balasubramanyam, A., Rahman, M. F., Indu Kumari, S., Mahboob, M. (2012). Oxidative stress induced by aluminum 
oxide nanomaterials after acute oral treatment in Wistar rats. Journal of Applied Toxicology, 32(6), 436-445.

Rowe, L. A., Degtyareva, N., \& Doetsch, P. W. (2008). DNA damage-induced reactive oxygen species (ROS) stress response in Saccharomyces cerevisiae. Free Radical Biology and Medicine, 45(8), 1167-1177.

Sánchez-Iglesias, S., Méndez-Álvarez, E., Iglesias-González, J., Muñoz-Patiño, A.r Sánchez-Sellero, I., Labandeira-García, J. L., \& Soto-Otero, R. (2009). Brain oxidative stress and selective behaviour of aluminium in specific areas of rat brain: potential effects in a 6-OHDA-induced model of Parkinson's disease. Journal of Neurochemistry, 109(3), 879-888.

Schneiderová, B., Demel, J., Zhigunov, A., Bohuslav, J., Tarábková, H., Janda, P., \& Lang, K. (2017). Nickel-cobalt hydroxide nanosheets: synthesis, morphology and electrochemical properties. Journal of Colloid and Interface Science, 499, 138-144.

Siddiqui, M. A., Kashyap, M. P., Kumar, V., Al-Khedhairy, A. A., Musarrat, J., \& Pant, A. B. (2010). Protective potential of trans-resveratrol against 4hydroxynonenal induced damage in PC12 cells. Toxicology In Vitro, 24(6), 1592-1598

Sriram, M. I., Kanth, S. B. M., Kalishwaralal, K., \& Gurunathan, S. (2010). Antitumor activity of silver nanoparticles in Dalton's lymphoma ascites tumor model. International Journal of Nanomedicine, 5, 753-762.

Sundar, L. S., Anjum, N. A., Ferro, M. C., Pereira, E., Singh, M. K., \& Sousa, A. C. M. (2017). Biocompatibility and biotoxicity of in-situ synthesized carboxylated nanodiamond-cobalt oxide nanocomposite. Journal of Materials Science \& Technology, 33(8), 879-888.

Tice, R. R., Agurell, E., Anderson, D., Burlinson, B., Hartmann, A., Kobayashi, H., ... Sasaki, Y. F. (2000). Single cell gel/comet assay: guidelines for in vitro and in vivo genetic toxicology testing. Environmental and Molecular Mutagenesis, $35(3), 206-221$

Uboldi, C., Orsière, T., Darolles, C., Aloin, V., Tassistro, V., George, I., \& Malard, V. (2015). Poorly soluble cobalt oxide particles trigger genotoxicity via multiple pathways. Particle and Fibre Toxicology, 13(1), 5-15.

Vijver, M. G., Peijnenburg, W. J., \& De Snoo, G. R. (2010). Toxicological mixture models are based on inadequate assumptions. Environmental Science \& Technology, 44, 4841-4842.

Wang, H., \& Joseph, J. A. (1999). Quantifying cellular oxidative stress by dichlorofluorescein assay using microplate reader1. Free Radical Biology and Medicine, 27(5-6), 612-616.

Zhang, C. L., Zeng, T., Zhao, X. L., Yu, L. H., Zhu, Z. P., \& Xie, K. Q. (2012). Protective effects of garlic oil on hepatocarcinoma induced by N-nitrosodiethylamine in rats. International Journal of Biological Sciences, 8(3), 363-374.

Zhao, J., Shi, X., Castranova, V., \& Ding, M. (2009). Occupational toxicology of nickel and nickel compounds. Journal of Environmental Pathology, Toxicology and Oncology, 28(3),177-208.

\section{Submit your manuscript to a SpringerOpen ${ }^{\circ}$ journal and benefit from:}

- Convenient online submission

- Rigorous peer review

- Open access: articles freely available online

- High visibility within the field

- Retaining the copyright to your article

Submit your next manuscript at $\boldsymbol{\nabla}$ springeropen.com 